\title{
Status of High Temperature Superconductor Magnet R\&D at BNL
}

\author{
R. Gupta, M. Anerella, J. Cozzolino, J. Escallier, G. Ganetis, A. Ghosh, M. Harrison, \\ A. Marone, J. Muratore, J. Schmalzle, W. Sampson and P. Wanderer
}

\begin{abstract}
We report the status and test results of the High Temperature Superconductor (HTS) cable and magnet R\&D at Brookhaven National Laboratory (BNL). If successful, this will enhance the performance and reduce the cost of operation of magnets that must absorb a large amount of energy. The need for developing this technology has been seen in a number of high field magnet applications for high energy colliders, and a medium field application in the proposed Rare Isotope Accelerator (RIA). The likelihood of the future use of HTS is improving because of the availability of longer and more uniform length tapes and cables and because of the ongoing construction and test experience at BNL and elsewhere. The design of a superferric quadrupole, that must survive the very high radiation environment of RIA, and operate at 20-40 K, is also presented.
\end{abstract}

Index Terms-High Temperature Superconductor, HTS, HTS coils, HTS magnets, Hybrid Magnets.

\section{INTRODUCTION}

$\mathrm{H}^{\mathrm{s}}$ TS offer two advantages over conventional Low Temperature Superconductors (LTS). They have the potential to generate much higher fields than LTS and they have the potential to allow magnet operation at a much higher temperature than 4 Kelvin. The Superconducting Magnet Division at BNL has been developing HTS technology for over five years to take advantage of these unique properties in some specialty applications [1-4]. Activities have ranged from testing tapes, wires and cables to designing, building and testing coils and magnets. The testing has been performed at various temperatures covering the whole range from $4 \mathrm{~K}$ (liquid helium) to $77 \mathrm{~K}$ (liquid nitrogen). The conductor of choice has been BSCCO 2212 in the form of Rutherford cable, and BSCCO 2223 in the form of tape. This paper presents the highlights of our construction and test activities while reviewing the progress made over the last five years. In addition, we also introduce a quadrupole design for the Rare Isotope Accelerator (RIA) that will operate at $20-40 \mathrm{~K}$ using the conductor available today. For high field applications, the performance of long length cables needs to improve by at least a factor of 2 .

Manuscript received October 21, 2003.

Authors arc associated with Brookhaven National Laboratory, Upton, NY 11973 USA. Email address of primary author: gupta@bnl.gov.

*This work was supported by U.S. Department of Energy under contract number DE-AC02-98CH10886.

\section{HTS CABLE TEST RESUlTS}

HTS Cables that are tested at the BNL cable test facility (see description in Table I) have been mostly cabled at Lawrence Berkley National Laboratory [5] with BSCCO 2212 wires from Showa Electric Wire \& Cable Company, Ltd., Japan [6]. All cable, except for an initial few were heat treated at Showa. The measured critical current (current for $1 \mu \mathrm{V} / \mathrm{cm}$ voltage drop) as a function of applied field at $4.2 \mathrm{~K}$ is shown in Fig. 1. In addition to those listed in Table I (and plotted in Fig. 1), several other cables were tested at liquid nitrogen and some at $4 \mathrm{~K}$. The critical current has gone up from less than 1 $\mathrm{kA}$ at $5 \mathrm{~T}$, in earlier Showa cables to over $6.7 \mathrm{kA}$ in short lengths $(\sim 1$ meter) and over $4.7 \mathrm{kA}$ in long length ( $\sim 50$ meter). In addition, we also observe that the cable itself is becoming more uniform (less variation in critical current) along the length. Showa is primarily carrying out these improvements for the SMES program at Chubu Electric Power Co., Japan.

TABLE I

DESCRIPTION AND PERFormanCE OF VARIOUS CABLES MEASURED AT THE BNL CABLE TEST FACILITY.

\begin{tabular}{lcccc}
\hline $\begin{array}{l}\text { Cablc } \\
\text { Designation }\end{array}$ & $\begin{array}{c}\text { No. of } \\
\text { Strands }\end{array}$ & $\begin{array}{c}\text { Strand } \\
\text { Diameter }\end{array}$ & $\begin{array}{c}\mathrm{I}_{\mathrm{c}}(5 \mathrm{~T}, 4.2 \mathrm{~K}) \\
(1 \mu \mathrm{V} / \mathrm{cm})\end{array}$ & $\begin{array}{c}\text { Datc } \\
\text { Tcsted }\end{array}$ \\
\hline I-00076-1 & 18 & $0.81 \mathrm{~mm}$ & $1827 \mathrm{~A}$ & 2-Mar-01 \\
S-00825-1a & 18 & $0.81 \mathrm{~mm}$ & $890 \mathrm{~A}$ & 3-Jun-01 \\
S-00825-1b & 18 & $0.81 \mathrm{~mm}$ & $990 \mathrm{~A}$ & 3-Jun-01 \\
S-00836-3 & 20 & $1.0 \mathrm{~mm}$ & $4750 \mathrm{~A}$ & 20-Nov-02 \\
S-00836-4 & 20 & $1.0 \mathrm{~mm}$ & $3252 \mathrm{~A}$ & 20-Nov-02 \\
S-B139-T-1 & 20 & $1.0 \mathrm{~mm}$ & $3452 \mathrm{~A}$ & 1-Apr-03 \\
S-B139-L-1 & 20 & $1.0 \mathrm{~mm}$ & $3100 \mathrm{~A}$ & 1-Apr-03 \\
S-R007B147-1 & 30 & $0.81 \mathrm{~mm}$ & $6748 \mathrm{~A}$ & 10-Apr-03 \\
S-R013B147-1 & 30 & $0.81 \mathrm{~mm}$ & $4861 \mathrm{~A}$ & 10-Apr-03 \\
S-R013B153-1 & 30 & $0.81 \mathrm{~mm}$ & $4033 \mathrm{~A}$ & 26-Aug-03 \\
S- R016B155-1 & 30 & $0.81 \mathrm{~mm}$ & $4784 \mathrm{~A}$ & 26-Aug-03 \\
\hline \hline
\end{tabular}

We plot the relative field dependence of the critical current in Fig. 2, by normalizing the curves in Fig. 1 to the $I_{c}$ value of each at $5 \mathrm{~T}$. In Fig. 2, we also superimpose the relative field dependence of a strand that was measured after extracting it from one of the cables. The self-field correction becomes less critical at $5 \mathrm{~T}$. Fig. 2 shows that all cables have a similar variation in critical current versus field, except at low field where self-field corrections (not applied here) make a significant difference in high performance cables. This implies that the measurements at one modest field $(\sim 5 \mathrm{~T})$ can be used to predict values at other fields (except at very low fields). 


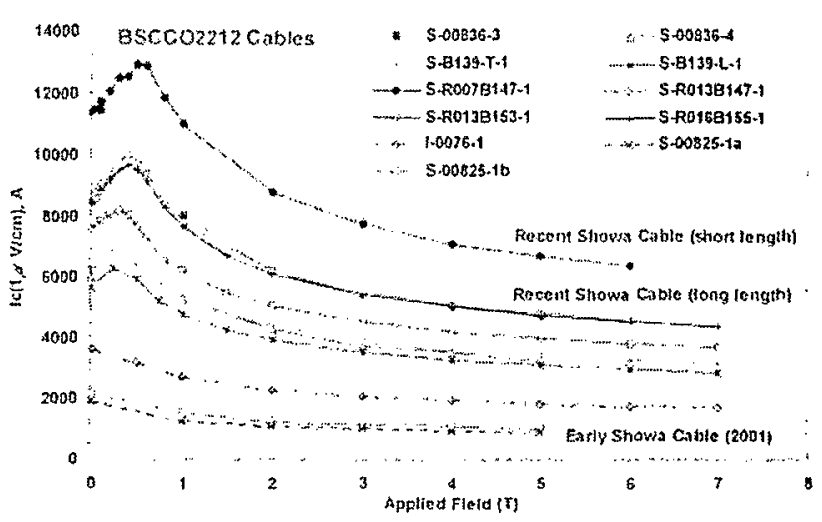

Fig. 1. Measurements of the critical current as a function of applied ficld for the cables listed in Table I.

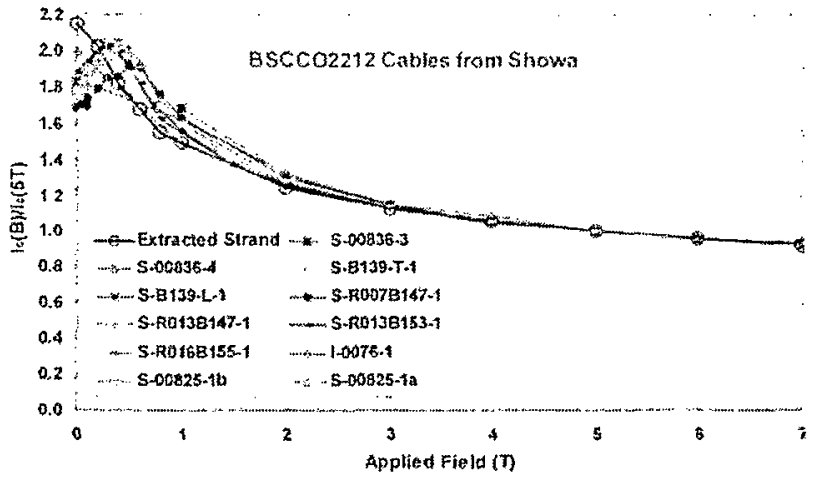

Fig. 2. Relative variation in the critical current as a function of applicd ficld for the cables listed in Table I (sce Fig. 1 for actual values). The rclative variation in the ficld dependence of an extracted strand is also included.

TABLE II

COILS AND MAGNETS BUILT AT BNL WITH BSCCO 2212 CABLE. $I_{G}$ IS THE MEASURED CRITICAL CURRENT AT $4.2 \mathrm{~K}$ IN THE SELF-FIELD OF THE COIL.

\begin{tabular}{|c|c|c|c|c|c|}
\hline $\begin{array}{c}\text { Coil / } \\
\text { Magnet }\end{array}$ & $\begin{array}{c}\text { Cable } \\
\text { Description }\end{array}$ & $\begin{array}{c}\text { Magnet } \\
\text { Description }\end{array}$ & $\begin{array}{l}I_{c} \\
(A)\end{array}$ & $\begin{array}{l}\mathrm{J}_{\mathrm{v}} \mathrm{s} \cap\left[\mathrm{J}_{\mathrm{r}}(5 \mathrm{~T})\right] \\
\left(\mathrm{A} / \mathbf{m m}^{2}\right) \\
\end{array}$ & $\begin{array}{c}\text { Self- } \\
\text { field, } T\end{array}$ \\
\hline $\begin{array}{c}\mathrm{CCO006} \\
\mathrm{DCC} 004\end{array}$ & $\begin{array}{l}0.81 \mathrm{~mm} \text { wirc, } \\
18 \text { strands }\end{array}$ & $\begin{array}{l}2 \text { HTS coils, } \\
2 \text { mm spacing }\end{array}$ & 560 & $\begin{array}{c}60 \\
{[31]}\end{array}$ & 0.27 \\
\hline $\begin{array}{c}C C 007 \\
\text { DCCO04 }\end{array}$ & $\begin{array}{c}0.81 \text { mm wirc, } \\
18 \text { strands }\end{array}$ & $\begin{array}{l}\text { Common coil } \\
\text { configuration }\end{array}$ & 900 & $\begin{array}{c}97 \\
{[54]}\end{array}$ & 0.43 \\
\hline $\begin{array}{c}\mathrm{CCO} 10 \\
\mathrm{DCC} 006\end{array}$ & $\begin{array}{l}0.81 \mathrm{~mm} \text { wirc, } \\
2 \mathrm{HTS}, 16 \mathrm{Ag}\end{array}$ & $\begin{array}{c}2 \text { HTS coils (mixed } \\
\text { strand) }\end{array}$ & 94 & $\begin{array}{c}91 \\
{[4 !]}\end{array}$ & 0.023 \\
\hline $\begin{array}{c}C C 011 \\
\text { DCCO06 }\end{array}$ & $\begin{array}{l}0.81 \mathrm{~mm} \text { wirc, } \\
2 \mathrm{HTS}, 16 \mathrm{Ag}\end{array}$ & $\begin{array}{l}74 \text { mm spacing } \\
\text { Common coil }\end{array}$ & 182 & $\begin{array}{r}177 \\
{[80]}\end{array}$ & 0.045 \\
\hline $\begin{array}{c}\mathrm{CC} 012 \\
\mathrm{DCC} 008 \\
\end{array}$ & $\begin{array}{l}0.81 \mathrm{~mm} \text { wirc, } \\
20 \text { strands }\end{array}$ & $\begin{array}{l}\text { Hybrid Design } \\
1 \mathrm{HTS}, 2 \mathrm{Nb}_{3} \mathrm{Sn}\end{array}$ & 1970 & $\begin{array}{c}212 \\
{[129]}\end{array}$ & 0.66 \\
\hline $\begin{array}{c}\mathrm{CCO} 23 \\
\mathrm{DCCO} 012 \\
\end{array}$ & $\begin{array}{l}1 \text { mm wirc, } \\
20 \text { strands }\end{array}$ & $\begin{array}{l}\text { Hybrid Design } \\
1 \mathrm{HTS}, 4 \mathrm{Nb}_{3} \mathrm{Sn}\end{array}$ & 3370 & $\begin{array}{c}215 \\
{[143]} \\
\end{array}$ & 0.95 \\
\hline $\begin{array}{c}\text { CC.026 } \\
\text { DCCO } 14\end{array}$ & $\begin{array}{l}0.81 \mathrm{~mm} \text { wirc, } \\
30 \text { strands }\end{array}$ & $\begin{array}{l}\text { Hybrid Common } \\
\text { Coil Design }\end{array}$ & 4300 & $\begin{array}{c}278 \\
{[219]}\end{array}$ & 1.89 \\
\hline $\begin{array}{c}\mathrm{CC} 027 \\
\mathrm{DCC} 014\end{array}$ & $\begin{array}{l}0.81 \mathrm{~mm} \text { wirc, } \\
30 \text { strands }\end{array}$ & $\begin{array}{c}2 \mathrm{HTS}, 4 \mathrm{Nb}_{3} \mathrm{Sn} \\
\text { coils (total } 6 \text { coils) }\end{array}$ & 4200 & $\begin{array}{c}272 \\
{[212]}\end{array}$ & 1.84 \\
\hline
\end{tabular}

\section{HTS MAGNET TEST RESULTS}

We have built and tested a number of HTS racetrack coils with a variety of tapes [3] and Rutherford cables [1]. In this paper we present the performance of recent magnets made with Rutherford cable. We use the common coil magnet design with racetrack coils [2] as an efficient vehicle to develop HTS technology. The racetrack coils discussed in this paper have 10 turns, a straight section of $300 \mathrm{~mm}$ and a minimum bend radius of $70 \mathrm{~mm}$. Table II summarizes the coils and the magnets tested, the critical current $\left(I_{c}\right)$ at $4.2 \mathrm{~K}$ measured in self-field, along with the maximum value of selffield in each case. We compute the engineering current density $\left(J_{e}\right)$ for the bare (un-insulated) cable in self-field and also at $5 \mathrm{~T}$ field using the field dependence shown in Fig. 2. The information in Table Il facilitates a relatively fair comparison between widely different cases. It is encouraging to see an increase in $J_{\mathrm{e}}(5 \mathrm{~T})$ by over a factor of seven in just a few years (fifth column in Table II).

A relatively easy and inexpensive quality assurance test [4] is performed when each coil is tested in liquid nitrogen $\left(\mathrm{LN}_{2}\right)$. At this initial stage of the $R \& D$, we incorporate many voltage taps (V-taps) - at least one every turn. Such a test $\left(\mathrm{LN}_{2}\right.$ testing) and test setup (V-tap at each turn) gives an. initial indication of a potential problem and its location which, in turn, may help find and rectify the cause of it. In Fig. 3, we plot $I_{c}$ at $\sim 77 \mathrm{~K}$, measured roughly for each turn going from inside to outside for the three most recent coils. The similar overall variation in all three coils (see Fig. 3 ) suggests that the primary source of this variation may be the self-field of the coil. The argument is further supported by the fact that (a) the variation in field with turn number is opposite to the pattern of $I_{c}$ seen in Fig. 3 and (b) the variation in field dependence in HTS is larger at higher temperature (as in $\mathrm{LN}_{2}$ testing) and at lower field. This argument, however, does not exclude the possibility of a constant degradation throughout.

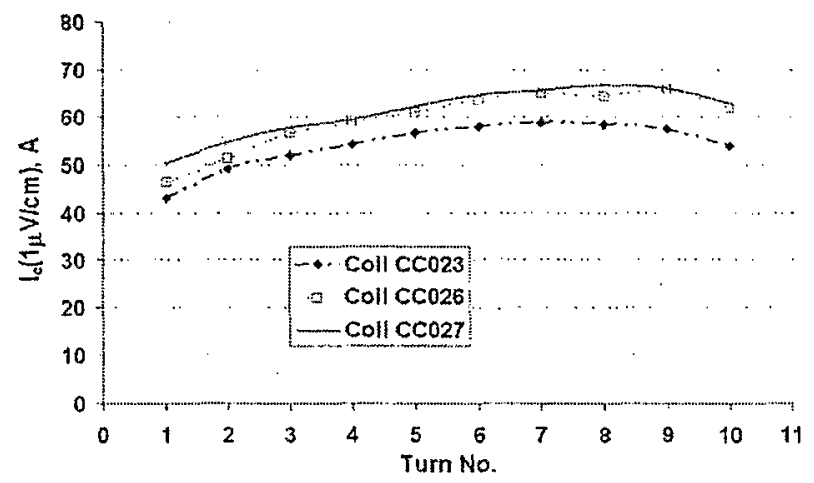

Fig. 3. Variation in $I_{\mathrm{c}}$ for cach turn at $77 \mathrm{~K}$ for the threc most recent coils.

Magnets DCC008, DCC012 and DCC014 were built to provide a background field on one or two HTS coils by two or four $\mathrm{Nb}_{3} \mathrm{Sn}$ coils (see Table II). The performance of the recent coils at $\sim 4.2 \mathrm{~K}$, along with the cable used, is shown in Fig. 4 . A point worth noting is that modern HTS cables now carry a respectable current in magnets. Since the carrying capacity of HTS remains virtually constant at high fields, the performance of HTS is already better than that of LTS at very high $(-20 \mathrm{~T})$ fields.

The test of HTS coil CC012 in magnet DCC008 and coil CC023 in magnet DCC012 were completed at background currents of $0 \mathrm{kA}, 3 \mathrm{kA}, 6 \mathrm{kA}$ and $9 \mathrm{kA}$. The test of magnet DCC014 with two HTS coils, CC026 (with cable S- 
R016B155-1) and CC027 (with cable S-R013B153-1), could only be performed without background field. The results of these measurcments are shown in Fig. 4. It may be pointed out that due large current carrying capacity of recent cables, the self-ficld generated by the HTS coils becomes significant. For example, the self-field of two HTS coils in a common coil configuration with $2 \mathrm{~mm}$ spacing between the two is over 1.8 $T$ (see Table II). Fig. 5 shows the field on the HTS and background field coils in magnet $\mathrm{DCC} 012$ when the current in the HTS coil is $2.3 \mathrm{kA}$ and in the $\mathrm{Nb}_{3} \mathrm{Sn}$ coils is $9 \mathrm{kA}$. The Field is not symmetric due to a non-symmetric configuration (3 coils).

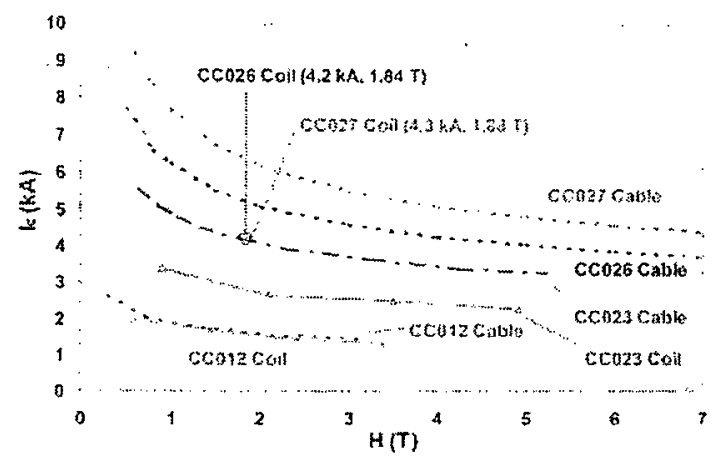

Fig. 4. A comparison of the coil perfornance (solid linc, with symbol) with the cable performance (dashed line, no symbol) for the coils wound with the recent HTS cable. The test results of coils $\mathrm{CC} 012$ and $\mathrm{CCO} 3$ are with and without the background ficld applied. The test results of coils CCO26 and CC027 are without the background ficld applicd (sclf-ficld only).

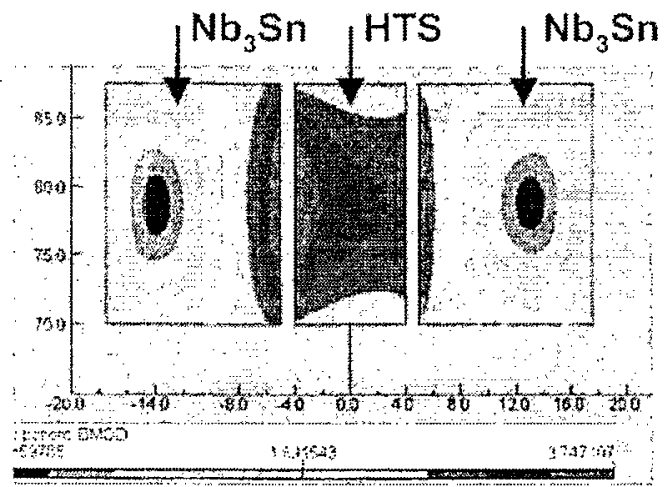

Fig. 5. Ficld on single HTS coil CC023 (middlc) and on the background ficld coils (on cither side) in magnet. DCCOI2 when the current in HTS coil is 2.3 $\mathrm{kA}$ and on $\mathrm{Nb}_{3} \mathrm{Sn}$ coils is $9 \mathrm{kA}$. The ficld is not expected to be symmetric because of odd number of coils.

To examine a possible degradation in cable, either due to bending or due to handling, the critical current of the cable in the coil is compared to the critical current of the cable measured before the coil was wound. Such comparisons are meaningful only if the cable has a small variation in the cable $I_{\mathrm{c}}$ along its length. For this reason, we make this comparison only for the recent coils.

The computed bending strain for a $70 \mathrm{~mm}$ coil radius in cable made with $1 \mathrm{~mm}(0.81 \mathrm{~mm})$ wire is $1.42 \%(1.16 \%)$ if one assumes wires to be sintered and $0.71 \%(0.58 \%)$ if not sintered. The cables on the two wide edges are generally sintered.
The test of DCCO14 had to be abandoned after two runs (two quenches) as the coil CC027 (the slightly inferior of the two coils) was damaged and become resistive at or around $4^{\text {th }}$ turn. It may be pointed out that each coil has 10 turns and there is at least one V-tap at each turn. The V-tap signals show that this turn (or section) was the weakest of the twenty turns in the two coils combined. The analysis presented here is preliminary as the test was being performed at the time of writing this paper. The cable and epoxy were found to have partially melted at the suspected location.

As compared to LTS, the transition from the superconducting state to the normal state as a function of current is slow in present HTS cables. In fact for a significant interval of current, the cable remains in a semi-resistive state before the critical current is reached. The generally accepted definition of critical current in HTS is the current that creates an average voltage gradient of $1 \mu \mathrm{V} / \mathrm{cm}$ across the length. This allows the possibility of much a higher gradient at a local spot in longer length cables/coils. In our earlier tests we allowed an HTS coils to be operated at a voltage gradient of 1 $\mu \mathrm{V} / \mathrm{cm}$. The overall coil was protected with the quench protection system with criteria (at times modified) that were used in LTS coils. In all previous cases coils were able to recover after the quench. However, with the improved performance in HTS, we operated these coils at $50 \%$ higher current $(4300 \mathrm{~A})$ than before. It seems that it was sufficient to damage the coil at the weakest spot. Moreover, the quench propagation velocities are very slow in HTS coils operating at low temperature $(\sim 4 \mathrm{~K})$ due to a large temperature margin.

To avoid such situations, quench detection criteria (methods) and thresholds must be revised. To avoid a local hot spot going undetected, coils that use long lengths of conductors should be operated at a significantly lower level than $1 \mu \mathrm{V} / \mathrm{cm}$ on the average. We should be able to protect HTS coils with these guidelines and after carrying some R\&D. However, the situation is expected to improve in future HTS cable, when the cables become more uniform and the transition from superconducting to normal state becomes faster (as in LTS).

\section{HTS QUADRUPOLE DESIGN FOR RIA}

Quadrupole magnets in the Fragment Separator for RIA [7] will be exposed to several orders of magnitude more radiation and energy deposition than typical beam line and accelerator magnets see during their entire lifetime. The lifetime dose of fast neutrons has been crudely estimated to be $10^{19}$ neutrons $/ \mathrm{cm}^{2}$ in the region of 0 to 30 degrees. At such a high radiation dose, various components of the magnet, like superconductor, insulation, etc. fail. Moreover, the heat load on the first quadrupole itself is estimated to be over $15 \mathrm{~kW}$.

The gradient requirements are such that they cannot be met by normal water-cooled resistive magnets. However, they can be met with commercially available HTS tape or wire operating at $20-40 \mathrm{~K}$. There are many advantages of using HTS over LTS. The change in critical current as a function of 
tcmperature is much smaller in HTS than in LTS. In addition, there is also a large saving in operating cost since the cost of removing energy at higher temperatures is significantly lower. Moreover, the control of the operating temperature can also be reduced by an order of magnitude.

We have developed a magnet design that minimizes the radiation and heat loads on superconducting coils by over an order of magnitude. An octant of the proposed super-ferric magnet design with $110 \mathrm{~mm}$ yoke aperture is shown in Fig. 6. The magnetic flux is funneled to create a high field on the pole tip to produce the desired gradient of $32 \mathrm{~T} / \mathrm{m}$. The design assumes an overall current density in coil to be in the range of 100-150 A/mm ${ }^{2}$. After years of R\&D, these current densities are now available at $20-40 \mathrm{~K}$ in commercially produced HTS tapes. The coils have been placed outward to increase their average angle from the target. This is motivated by the angular distribution of the neutron yield in the fragment separator region after the target. It is shown that the neutron dose falls by a factor of 50 or more if the coils are placed at an average angle of 30 degree or more as measured from the target [8].

The HTS tape will be co-wound with stainless steel tape with latter acting as insulation. Insulation remains the major concern in the magnets that must face very high radiation doses. Stainless steel tape, being a metal, is highly radiation resistant and is the critical part of the overall design. A double pancake coil of BSCCO223 tape and high strength stainless steel tape insulation has already been wound and successfully - tested at BNL as a part of another project [9].

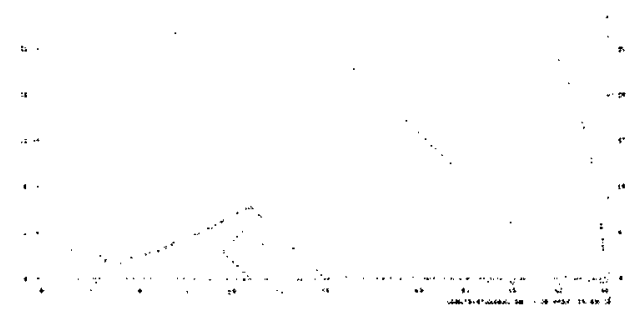

Fig. 6. An octant of the proposed super-ferric quadrupole design for the RIA fiagment separator that produces the required ficld gradient. The coils are placed away from the magnet center to reduce the radiation dosc.

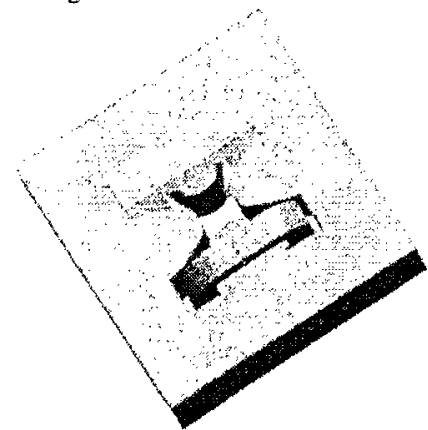

Fig. 7. The warm iron super-ferric quadrupole design for RIA. The two racctrack coils producc quadrupoic symmetry in the cross scetion. The upper coil is rendered in its own cryostat and the lower coil is not.

A significant reduction in the heat load in the magnet is achieved by adopting a warm iron design. A preliminary engineering concept of this warm design is shown in Fig. 7. The extent of saving in heat load is apparent from the initial estimates that indicate that the heat load on the cold coil volume is a few hundred watts whereas on the iron is $\sim 15 \mathrm{~kW}$.

The magnet will be built with simple racetrack coils. To simplify the coil winding and to reduce the cold volume in the magnet ends, we adopt a symmetric two coil design that has quadrupole symmetry in the $2-d$ cross section and dipole symmetry in the ends. The ends of the racetrack coils do not cross beam tube since the coils are placed at a radius much higher than the beam tube in magnet cross-section. This configuration, however, creates axial fields in the two ends. These fields cancel each other. This feature, to be verified with beam physicists, should be acceptable for beam line magnets.

\section{SUMMARY}

Significant progress has been seen in the HTS conductor. HTS cables now carry significant current in magnets. The present $1 \mu \mathrm{V} / \mathrm{cm}$ definition of $\mathrm{I}_{\mathrm{c}}$ is too liberal for long magnets operating at $\sim 4 \mathrm{~K}$ temperature for generating high field. There is a need to develop new criteria for magnet protection and magnet operation that may be different from LTS magnets and also different from the $1 \mu \mathrm{V} / \mathrm{cm}$ definition of $I_{c}$ in HTS.

\section{ACKNOWLEDGMENT}

We would like to thank Showa Electric Wire \& Cable Corporation, Japan for providing the pre-reacted wires and cables for this R\&D. BSCCO2212 development at Showa is sponsored by Chubu Electric Power Co., Inc., Japan. The cables were made at Lawrence Berkeley National Laboratory (LBNL) with wires from Showa. Regular discussions with Dr. Hasegawa (Showa) and Dr. Scanlan (LBNL) have been very useful. We would like to acknowledge important contributions of our technicians (in particular, Joseph Gormley, Glenn Jochen and Frank Skidmore). R\&D on RIA quadrupole has been carried out in collaboration with Dr. A. Zeller from Michigan State University.

\section{REFERENCES}

[1] R. Gupta, ct al., "R \& D for Accelcrator Magncts with Rcact and Wind High Temperaturc Supcrconductors," International Conference on Magnet Technology (MT17) at Gencva, Switzcrland (2001).

[2] R.C. Gupta, "A Common Coil Design for High Ficld 2-in-1 Accclerator Magncts," Presented at the 1997 Particle Accelcrator Conference in Vancouver, Canada (1997).

[3] W. Sampson, et al., "Persistent Current effects in BSSCO Common Coil Dipolc," Applicd Supcrconductivity Conference at Virginia Beach, USA (2000).

[4] A. Ghosh, ct al., "Batch Testing of BSCCO 2212 Cablc in Subcoolcd Liquid Nitrogen," Intcrnational Conference on Magnet Technology (MTI7) at Geneva, Switzcrland (2001).

[5] D. Dictderich, et al, "Critical Current Variation as a function of Transverse Stress of Bi-2212 Rutherford Cables," Applicd Supcrconductivity Confercnec at Virginia Bcach, USA (2000).

[6] T. Hascgawa, "12kA HTS Rutherford Cablc," $18^{\text {th }}$ International Conference on Magnet Technology, Morioka, Japan, October 2003.

[7] Rarc Isotope Accelcrator (RIA) Websitc, http://www.phy.anl.gov/rial.

[8] T. Kurosawa, ct al., "Ncutron Yicld from thick $\mathrm{C}, \mathrm{Al}, \mathrm{Cu}$ and $\mathrm{Pb}$ targets bombarded by $400 \mathrm{McV} /$ nuclcon $\mathrm{Ar}, \mathrm{Fc}, \mathrm{Xc}$ and $800 \mathrm{McV} /$ nuclcon $\mathrm{Si}$ ions," Phys Rev C, Vol 62, 044615.

[9] W. Sampson, "Unpublished Report". 